\title{
O RÁDIO NO MERCOSUL E NA UNIÃO EUROPEIA - OS CASOS DE PORTO ALEGRE E BARCELONA
}

\author{
DORIS Fagundes HaUSSEN*
}

A configuração mundial em grandes blocos econômicos é uma realidade. A UE - União Européia - com os seus 370 milhões de habitantes criou o maior mercado do mundo, impulsionando as trocas comerciais entre os seus 15 Estados-membros, numa área de 3,3 milhões de metros quadrados e com um PIB - Produto Interno Bruto-de 7,2 trilhões de dólares. O Mercosul, por seu turno, configura-se com uma população de 193,5 milhões de habitantes, quatro países membros-Brasil, Argentina, Paraguai e Uruguai, uma área de 11,8 milhões de metros quadrados e um PIB de cerca de 900 bilhões de dólares ${ }^{1}$.

Em dezembro de 1995, foi assinado um acordo preliminar para a formação de uma área de livre comércio entre o Mercosul e a União Européia, significando um primeiro passo para a aproximação entre os dois blocos econômicos. Esta medida demonstra a velocidade com que os acordos econômicos avançam trazendo consigo várias interrogaçōes: Como estão sendo tratados os temas relativos à cultura e à cidadania? Que medidas estăo sendo tomadas pelos governos em relação à Comunicação? De que forma os meios de comunicação estão se ajustando? Qual tem sido o papel específico do Rádio no atual contexto?

* Jornalista, professora da Famecos/PUCRS e da Fabico/UFRGS.

1 Fontes: SalGado, Eduardo. «Uma ponte sobre o Atlântico» in Revista Amanhã n. 103, Porto Alegre, Plural Comunicações Ltda., janeiro de 1996, p.48, e Secretaria Estadual do Desenvolvimento e Assuntos Internacionais - Disque Mercosul, 1999. 
O presente trabalho procura responder a algumas destas questões identificando na programação radiofônica das emissoras das cidades de Porto Alegre e de Barcelona de que forma são abordados os temas relativos ao Mercosul e à União Européia. As duas cidades foram escolhidas pela sua característica comum de pertencerem a regiões de forte tradição cultural e que, hoje, também fazem parte de blocos que, por sua vez, buscam criar uma cidadania comum. A escolha do rádio deveu-se, por seu turno, ao fato do veículo, pelas suas características próprias, ser o mais próximo da comunidade.

A análise foi efetuada, inicialmente, a partir do estudo dos processos de integração na Europa e na América do Sul. Nestes, de um lado apresenta-se o gradualismo dos processos de industrialização e de integração econômica europeus, geralmente combinados com o desenvolvimento de padrões sociais e políticos democráticos; do outro lado, constata-se o ritmo acelerado em que é feito o processo de industrialização e de integração do Mercosul, como decorrência das necessidades sociais e econômicas dos países que o compõem (Trindade, 1995) ${ }^{2}$.

Em relação ao Rádio, foi efetuada a seleção das três emissoras mais ouvidas nas duas cidades e nelas, os três programas de cunho jornalístico-cultural de maior audiência. No caso de Porto Alegre, foi consultada a pesquisa do IBOPE e, no de Barcelona, a pesquisa do EGM - Estudio General de Medios. Durante uma semana realizou-se a audição e a gravação dos programas nas respectivas cidades e, posteriormente, a decupagem. Paralelamente, foram sendo efetuadas as entrevistas e leituras necessárias para a análise do material coletado. $\mathrm{O}$ material relativo às emissoras de Barcelona foi gravado em abril de 1997 e o de Porto Alegre em maio de $1998^{3}$. A pesquisa não se propõe a realizar um estudo comparado, no sentido estrito, uma vez que as realidades gaúcha e catalã apontam muitas diferenças, mas, procura analisar o caso de duas localidades que passam por processos semelhantes, possuindo algumas características comuns.

\section{A construção da União Européia e do Mercosul}

As raízes do processo de integração europeu podem ser encontradas, em realidade, após o término da Segunda Guerra Mundial, em 1946, no

2 TRINDADE, Hélgio. «A cooperação EU/Mercosul em matéria de ciência e tecnologia, formação, educaçāo e cultura». Conferência apresentada no seminário EU/Mercosul, Acordo Marco Internacional de Cooperaçāo, Porto Alegre, 8/12/95.

3 Uma gravação já havia sido feita em outubro de 1996 e, a reconfirmaçāo, em 1998. A primeira versāo foi realizada pela bolsista de Iniciação Científica da Fapergs, Vanessa Oppelt Conte, e a segunda, pela bolsista Fapergs, Vilmarise de Bairros Franceschi. 
discurso pronunciado por Winston Churchill, em Zurique, quando foi lançada a idéia da construção de «uma espécie de Estados Unidos da Europa» ${ }^{4}$. Dois anos depois, em 1948, os dirigentes políticos da Europa, reunidos em Haia, propuseram a constituição de um parlamento europeu com competência para pôr em execução as medidas necessárias para a realização da unidade política da Europa. No ano seguinte, 1949, foi criado, em Estrasburgo, o Conselho da Europa. Em 1950, no entanto, é que foi divulgado o documento-base da construção européia, pelo Ministro dos Negócios Estrangeiros Franceses, Robert Schuman. Nele, foi proposta a reconciliação franco-alemã e a criação, de imediato, da Comunidade Européia do Carvão e Aço (cujo Tratado foi assinado em 1951) e, a mais longo prazo, dos Estados Unidos da Europa.

O método proposto por Schuman para atingir os propósitos da união européia previa que a Europa não poderia construir-se de uma só vez, devendo ser criada entre os europeus uma solidariedade de fato, sob o ponto de vista econômico, social e cultural, através de realizações concretas. Também deveriam ser estabelecidas bases comuns de desenvolvimento, pondo em relação as produções de base. Daí a proposta de criação da Comunidade do Carvão e do Aço. Estava prevista, ainda, a criação de instituições e regras comuns e a nomeação de uma alta autoridade dos governos dos Estados-membros, com competência para tomar decisões a serem acatadas. Após 1951, uma série de acordos foram sendo assinados (em 1957 foi firmado o Tratado de Roma que deu origem à Comunidade Econômica Européia) até que, em 1992, finalmente, a União Européia tornou-se realidade.

Na América Latina, a idéia da integração teve o apoio da CEPAL Comissão Econômica para a América Latina (criada em 1948 pelas Nações Unidas), que via nela a única forma de contornar a estreiteza dos mercados internos, uma condição necessária para viabilizar os programas de desenvolvimento econômico. Mas, apenas com a criação da ALALC - Associação Latino-Americana de Livre Comércio, em 1960, é que iria ser possível dar início a essa concretização (em 1980 foi assinado o Tratado de Montevideu que criou a ALADI - Associação Latino-Americana de Integração, sucessora da ALALC). Os primeiros anos da experiência de integração na América Latina foram difíceis e o comércio dentro da região não apresentou a expansão desejada. Diversas iniciativas de integração sub-regional surgiram como consequência do descontentamento que se seguiu, sendo que foram apresentadas como estratégia alternativa para avançar no rumo de

4 GABRICcI, Leonello. A integraçāo européia. In PLÁ, Juan Algorta. O Mercosul e a Comunidade Europeia. Uma abordagem cooperativa. Porto Alegre, Edufrgs/Goethe, 1994, pp. 14-23. 
uma integração mais completa. No entanto, foi apenas na década de 80 , quando outras experiências ao nível mundial começaram a se concretizar, é que mecanismos concretos de integração começaram a ser adotados, resultando na configuração do MERCOSUL.

Em julho de 1986, em Buenos Aires, foi assinada a Ata para a integração Argentino-Brasileira que instituiu o Programa de Integração e Cooperação Econômica (PICE). O objetivo era propiciar um espaço econômico comum aos dois países. Em 1988, com vistas a consolidar o processo de integração, Brasil e Argentina assinaram o Tratado de Integração, Cooperação e Desenvolvimento que previa a eliminação de todos os obstáculos tarifários e não tarifários ao comércio de bens e serviços e a harmonização de políticas macro-econômicas. $O$ Tratado foi aprovado pelos dois países em 1989. Em dezembro de 1990, foi assinado o Acordo de Complementação Econômica n.14 que já refletia a dinâmica e os critérios a serem estabelecidos pela realidade do MERCOSUL. Em julho de 1990, foi assinada a Ata de Buenos Aires que fixou o prazo de dezembro de 1994 para a confirmação definitiva do mercado comum entre Brasil e Argentina. Em agosto de 1990, o Paraguai e o Uruguai foram convidados a juntar-se ao processo em curso, o que levou à assinatura, pelos quatro países, em 26 de março de 1991, do Tratado de Assunção para a constituição definitiva do Mercosul, a partir de $1 .^{\circ}$ de janeiro de 1995.

\section{O espaço da comunicação}

Esta nova forma de integração da economia e de espaços nacionais realiza-se sob a diretriz expansiva da economia mundializada, exigindo uma redefinição dos sistemas de comunicação que conformam as redes de interconexão de um sistema cada vez mais internacionalizado. Por outro lado, os atores principais que estão operando estes espaços são as empresas transnacionais. Segundo Murciano (1994), no interior destes macroespaços, a Comunicação - em um sentido amplo - constitui um elemento central: projeta as novas redes, os novos serviços, o consumo, produz e difunde a informação e a cultura, é agente de industrialização, modernização, desenvolvimento. «A comunicação é, portanto, o elemento que enlaça os macroprocessos com a dinâmica global do sistema. A comunicação, pois, é tecido, é nexo que permite uma articulação flexível entre as dinâmicas do local, do nacional, do regional e do mundial» (Ibid. p. 28) ${ }^{5}$.

5 MURCiano, Marcial. Lo global y lo local en las estructuras de comunicacion intemacionales. Monopolios o redes. Suplemento TE-LOS - Cuadernos de Comunicación, Tecnologia y Sociedad. Madrid, Fundesco, 1994, pp. 27-32. 
Apesar da importância fundamental da Comunicação na constituição dos grandes blocos, este fato inicialmente não teve reconhecimento. No caso europeu, foi apenas a partir de 1986, com a organização do «Livro Verde», que se iniciou uma discussão sistemática sobre as Políticas de Comunicação. No caso do Mercosul, o Protocolo 16, firmado em 10 de dezembro de 1986, aborda a questão das Comunicações, estabelecendo um programa de cooperação na área das telecomunicações, visando inicialmente as redes digitais, os serviços telemáticos e os sistemas de transmissão. O decreto n.99.431, de $3 \mathrm{l}$ de julho de 1990, prevê que as emissoras de radiodifusão poderão transmitir programas em idioma estrangeiro estes programas deverão ser aprovados pelo Ministério de Relações Exteriores. Também diz que a transmissão ou retransmissão de programas produzidos por emissoras de outros países não poderão contrariar disposições da legislação brasileira. O tema específico "Comunicação» só vai aparecer em 1995, quando é formado o Subgrupo de Trabalho número um, identificado pela sigla SGT1 - Comunicações, que possui função essencialmente técnica. No entanto, não há nenhum registro sobre uma "política» de Comunicação.

Um estudo realizado sobre as «Políticas de Comunicação no Mercosul» (Brittes,1998) analisou comparativamente as Constituições Federais dos países membros do Bloco e constatou que «a persistência do Estado-Nação é o contrato mais sólido entre os atores no interior do ambiente regional». Isso significa que as decisões não têm força supranacional, uma vez que é preservada a autonomia dos Estados-partes. Desta forma, é muito difícil que a configuração do bloco comum seja percebida pela população em geral como uma entidade maior que a dos estados-nações que o compõem. $\mathrm{E}$, como consequência, que o assunto tenha destaque na pauta dos veículos de comunicação.

\section{Porto Alegre e Barcelona}

Porquê Porto Alegre e Barcelona? Não apenas pela sua cultura regional. Também pela situação geográfica das duas cidades dentro dos respectivos blocos. Porto Alegre é a capital do Rio Grande do Sul, estado brasileiro que faz fronteira com o Uruguai e a Argentina. Esta proximidade é justamente uma das causas do forte regionalismo/nacionalismo do povo gaúcho que, através da história, lutou inúmeras vezes para a demarcação das fronteiras do país, nos confrontos entre portugueses e espanhóis.

Barcelona, por sua vez, também possui uma tradição cultural forte - é capital da Catalunha que se considera «uma nação sem estado» dentro da Espanha. Conta, inclusive, com idioma próprio - o catalão, utilizado além do espanhol - e pertence à região fronteiriça com a França. 
Quanto aos dados iniciais sobre as duas regiões se pode apontar o seguinte: o Rio Grande do Sul possui um território de $282.062 \mathrm{~km}^{2}$ e uma população de cerca de nove milhões e 500 mil pessoas. Conta, atualmente, com 427 municípios. O estado faz fronteira ao sul com o Uruguai, ao oeste com a Argentina, ao leste com o Oceano Atlântico e ao norte com o estado de Santa Catarina. O Rio Grande do Sul foi a última região do Brasil a ser povoada: somente na segunda metade do século XVIII é que o povoamento começou a atingir o interior. Até então, apenas os jesuítas haviam se instalado na região das Missões, a partir de 1619.

Porto Alegre, por sua vez, foi fundada em 1752, por casais de açorianos, chamando-se, então, Porto dos Casais. Em 1822 passou à categoria de cidade. Possui, atualmente, $502,5 \mathrm{~km}^{2}$ de área e um milhão e $300 \mathrm{mil}$ habitantes, aproximadamente. A região metropolitana conta com cerca de três milhões e 200 mil habitantes.

A Catalunha, na Espanha, abrange parte dos Pirinéus e área oriental da bacia do rio Ebro, formada por planícies estépicas, mas com a parte central irrigada. Possui uma área de $31.930 \mathrm{~km}^{2}$ e cerca de seis milhões de habitantes. Situa-se no norte do país fazendo fronteira com a França e separando-se da Itália pelo mar Mediterrâneo. É uma das 17 comunidades autônomas que compõem a Espanha.

Barcelona é a capital da Catalunha. Possui uma área de $99,07 \mathrm{~km}^{2}$ e $500 \mathrm{~km}^{2}$ na região metropolitana. A população da cidade é de cerca de um milhão e 700 mil habitantes e de três milhões na região metropolitana, tendo, portanto, alta densidade populacional. Barcelona é o porto mais importante da Espanha, às margens do Mediterrâneo, situando-se ao noroeste da Península Ibérica. É uma das quatro províncias que configuram a Comunidade Autônoma da Catalunha, junto com Gerona, Tarragona e Lérida. A cidade foi capital dos Visigodos, independente em 874, anexada a Aragão no século XII, tendo sido um dos maiores centros bancários e comerciais da Europa no século XIII. A descoberta da América afetou-lhe a prosperidade que só foi reconquistada no século XIX.

\section{A estrutura da radiodifusão}

Quanto à radiodifusão nos dois países, a situação brasileira indica que há atualmente em funcionamento no país 2936 emissoras de rádio e 257 canais de TV. Das de rádio, 2867 são comerciais e 69 são educativas; das de TV, 237 são comerciais e 20, educativas. Na Espanha há 3231 emissoras de rádio. Dessas, 2205 são públicas e 1026 privadas, distribuídas principalmente nos últimos vinte anos após a consolidação da democracia. Quanto à televisão, há três redes comerciais: Antena 3, Tele 5 e Canal Plus, e duas redes públicas: TVE 1 e TVE 2 , cada uma com vários canais afiliados pelo 
país. Pesquisas indicam que as emissoras privadas detêm $87 \%$ da audiência (Fonte: Revista Imprensa n.92).

O Rio Grande do Sul conta atualmente com 323 emissoras de rádio das quais 31 situam-se em Porto Alegre, sendo 15 em AM e 16 em FM. A maioria é de caráter privado, sendo apenas três diferenciadas: uma é estatal, da Universidade Federal do RGS (em AM), outra pertence à Fundação Piratiní, de caráter público (em FM), e uma terceira é educativa, em AM, de propriedade da Fundação Educacional Padre Landell de Moura (FEPLAM). Quanto à televisão, há seis canais, sendo um da Fundação Piratiní. Das demais cinco emissoras, quatro são afiliadas a redes nacionais: o canal 12 à Rede Globo, o canal 4 à Rede Manchete, o canal 5 à Rede do SBT e o canal 10 à Rede Bandeirantes. $O$ canal 2 é apenas regional. Todos os canais possuem retransmissoras no interior do Estado.

No âmbito do Mercosul, por iniciativa de um grupo de emissoras privadas, foi criada uma rede de rádio entre os quatro países membros (mais uma emissora do Chile), a "Rede Cone Sul de Comunicações», integrada pelas rádios Gaúcha Sat, de Porto Alegre/Brasil; Nandutí, de Assunción/Paraguai; Carve, de Montevidéu, no Uruguai; Mitre, de Buenos Aires, Argentina e a Cooperativa, de Santiago do Chile. A rede foi criada em junho de 1993, em Porto Alegre, quando os cinco diretores das emissoras assinaram um acordo formal. $\mathrm{O}$ objetivo era o de que cada rádio fosse «uma fonte de informações para as demais» e que além do intercâmbio técnico e de informações, a rede contemplasse aspectos comerciais, onde cada emissora representasse as demais em seu país. Em setembro de 1994, em Assunción, no quarto encontro entre os diretores e executivos da Rede, foram aprovados os estatutos sociais dando personalidade jurídica à sociedade.

A proposta inicial da rede era a de um intercâmbio de notícias e troca de boletins diários sobre os assuntos de interesse dos países integrantes, além da produção de um programa semanal entre as cinco emissoras. Mas, devido à barreira do idioma (português/espanhol), a proposta foi alterada. Atualmente, as informaçōes procedentes do Mercosul são apresentadas pelos locutores das respectivas emissoras, nos idiomas próprios, sem tratamento diferenciado das demais notícias. Nesse sentido, conforme Marques de Melo (1997:7), o principal desafio comunicacional do Mercosul «reside na superação das barreiras linguísticas que ainda subsistem no conjunto das nossas populações. Torna-se urgente um vasto projeto de cooperação cultural, começando pela mútua necessidade do aprendizado do idioma espanhol no Brasil e do português na Argentina, no Uruguai e no Paraguai».

Outra iniciativa foi a da rede de rádio «VRM - Via Radiofônica do Mercosul» - com 21 emissoras integradas do Rio Grande do Sul, Uruguai e Argentina. O fato de as iniciativas de integração no âmbito da Comunicação estarem a ser adotadas pelas instituições privadas indica, portanto, 
a falta de uma política específica para o setor por parte da organização mais ampla do Mercosul. A questão, por outro lado, salienta uma das características da globalização que tem provocado o encolhimento do raio de ação do estado nacional e deixado a cargo da iniciativa privada a organização da área. Uma característica que também está presente na estruturação dos demais blocos regionais.

Em relação à Espanha, a configuração das emissoras de rádio é constituída por emissoras públicas - do Estado, das comunidades autônomas e dos municípios - e privadas, compostas pelas grandes cadeias, pelas emissoras independentes e pelas rádios livres. Em Barcelona, é possível captar-se todos estes tipos de emissoras, em torno de 165 . As cadeias nacionais, emitidas desde Madrid, são uma tradição no país. Assim, recebe-se as transmissões da Rede Nacional da Espanha que conta com as cadeias das Rádios 1 (49 centros emissores), Rádio 2 (45 centros emissores), Rádio 3 (para público jovem) e Rádio 4 (emitida em catalão).

Relativamente às emissoras autonômicas, a Corporação Catalã de Rádio e Televisão - CCRTV - conta atualmente com quatro cadeias constituídas por 87 emissoras. Todas emitem em catalão, em FM, 24 horas por dia. As «cabeceiras" são a Catalunya Radio, com 28 outras emissoras, captadas em todo o território catalão. A programação é generalista: a RAC-105 que entra em cadeia com 22 outras emissoras e possui uma programação musical para público adulto/jovem; a Catalunya Informação, que entra em cadeia com outras 12 emissoras e opera 24 horas "all news» e a Catalunya Música, com uma programação de música clássica e que opera em cadeia com outras 25 emissoras. As rádios autônomas funcionam com o financiamento de impostos aprovados pelos parlamentares regionais e por publicidade.

Quanto às emissoras privadas, a Catalunha (incluindo Barcelona) conta com três grandes cadeias nacionais: a Unión Rádio: SER - Antena3; a COPE e a Onda Cero. Além destas, há a Cadeia Top-40, bem como 32 emissoras catalãs independentes e um grande número de rádio livres, estas com pouco alcance e não legalizadas.

\section{Os programas mais ouvidos em Barcelona}

Na Espanha como um todo - já que há emissão para todo o país, desde Madrid - os programas de rádio mais ouvidos são Hoy por Hoy, da cadeia SER, com cerca de dois milhões de ouvintes, seguido por La Mañana, da cadeia COPE, com um milhão e 700 mil ouvintes e, em terceiro, Protagonistas, da cadeia Onda Cero, com mais de um milhão e 500 mil ouvintes. 
Em Barcelona, os três programas mais ouvidos selecionados para a análise, de acordo com a pesquisa do EGM (Estudio General de Medios), situam-se no formato "magazine informativo» e são transmitidos pela manhã. A estrutura dos três programas é semelhante, com poucas variações, à exceção da duração - Els Matí de Catalunya Ràdio dura quatro horas ( $8 \mathrm{~h}$ às 12h); Protagonistas, da Onda Cero, dura cinco horas ( $8 \mathrm{~h}$ às $13 \mathrm{~h}$ ) e Hoy por Hoy, da SER, dura seis horas e 20 minutos, das $6 \mathrm{~h}$ às $12 \mathrm{~h} 20 \mathrm{~m}$. $\mathrm{O}$ primeiro é emitido em catalão e os dois últimos em castelhano. Os três programas abrem espaço para a participação de ouvintes, ao vivo, por telefone. As emissoras que emitem os programas têm uma programação geral incluída no formato "generalista».

Analisando-se a proporção de assuntos locais, regionais, nacionais e internacionais constata-se o seguinte: o programa El matí de Catalunya Ràdio tem a maior preponderância de temas regionais, seguido, na ordem, pelos temas nacionais, internacionais e locais (considerando-se que Barcelona concentra mais da metade da população catalã, neste caso os temas regionais são também de interesse local. Nesta última classificação situamse os temas como acidentes na cidade, agenda cultural, etc.). O programa Protagonistas dá ênfase preponderante aos temas nacionais, seguido pelos internacionais, e muito poucos temas regionais e locais. Por fim, o programa Hoy por Hoy também tem caráter nacional mas com maior peso aos assuntos regionais, incluídos na sua rede regional, das $7 \mathrm{~h}$ às $8 \mathrm{~h} 30 \mathrm{~m}$. Por último, em quase igualdade de proporção, são abordados os temas internacionais.

Em relação a assuntos relativos à União Européia, pode-se dizer que os programas abordam pouco. Na semana de audiência dos mesmos, foram tratados os seguintes temas: asilo político na UE (de interesse para o país devido ao terrorismo da ETA); a política para o setor olivareiro (setor chave da economia espanhola); fiscalização da UE referente à peste porcina em Lleida (Catalunha); informe da UE com os índices sobre a Espanha apontando a possibilidade do país se integrar com o Euro, a moeda única; índices da UE sobre leitores indicando que na Espanha "publica-se muito e lê-se pouco" (apenas 50\% dos espanhóis lêem um livro por ano). Evidentemente, outros assuntos dos países europeus aparecem nas notícias e comentários, como os das eleições da França e na Grã-Bretanha que foram tema de destaque na referida semana, devido à sua atualidade. No entanto, entram na relação de interesse com as demais notícias da Europa, não sendo especificamente abordados como da União Européia. Um dado interessante ocorreu no programa "Hoy por Hoy", do dia 21 de abril, em que Iñaki Gabilondo, ao entrevistar alguns estudantes sobre assuntos universitários, perguntou se eles «se sentiam como europeus" e estes vacilaram e acabaram respondendo que «os jovens não entendem muito de Maastricht». 
No entanto, segundo Antoni Bassas, da Catalunya Rádio ${ }^{6}$, a informação sobre a União Européia vem crescendo gradativamente e salienta a vocação europeísta catalã: «Nem que seja por proximidade geográfica, a Catalunha tem uma vocação européia muito mais clara que outras regiões da Espanha. E isto está dito por pessoas como os escritores Garcia Marquez e Vargas Llosa que se instalaram em Barcelona - mesmo no período franquista - porque percebiam um ambiente mais aberto. Isto não é algo novo, a partir da entrada na Espanha na União Européia, mas é a nossa maneira de ser».

Fazendo um balanço geral observa-se que El matí de Catalunya Rádio, produzido e apresentado desde Barcelona, constitui-se em um programa de interesse específico para a comunidade catalā, no sentido em que usa o idioma catalão na sua apresentação (e, evidentemente, na prática só esta comunidade o domina - e nem todos os habitantes da Catalunha utilizam este idioma, uma vez que há muitos migrantes de outros estados, principalmente andaluzes que falam castelhano, além de estrangeiros que dominam melhor este idioma). Em relação ao conteúdo, há também predominância de temas regionais (nos de destaque em que há maior aprofundamento e tempo destinado) embora com um bom equilíbrio entre estes $(37,1 \%)$, os temas nacionais $(35,2 \%)$ e os internacionais $(19,4 \%)$ no que se refere a notícias. Os temas especificamente locais, referentes a Barcelona, absorvem $8,2 \%$ do total.

O programa Protagonistas, por sua vez, é o que tem mais cunho nacional, embora seja produzido parte em Madrid e parte em Barcelona. E isto, como salienta Parés i Maicas ${ }^{7}$, apesar de o apresentador Luís del Olmo procurar defender a Catalunha quando possível (quando atacam o seu presidente Jordi Pujol, por exemplo). No entanto, «ao encontrar-se com a dualidade de fazer um programa nacional com conteúdos catalães, opta pelo primeiro devido à audiência e ao alcance da publicidade já que se trata de uma emissora privada». O programa é o de cunho mais popular dos três, ao entrevistar artistas nacionais muito populares e ao usar bastante música deste tipo (sevilhanas, etc.) e com bastante espaço para o humor - dois por semana (já foram três). Também os seus quadros permanentes apontam nesta direção. Segundo a produtora Núria Villamayor ${ }^{8}$ «o programa pretende elevar o estado de ânimo dos ouvintes», não significando que seja

6 Bassas, Antoni. Diretor e apresentador do programa «Els matí de Catalunya Rádio». Depoimento à autora. Barcelona, 02/10/97.

7 Parés I Maicas, Manuel. Professor da Universidade Autônoma de Barcelona. Depoimento à autora. Barcelona , 24/07/97.

8 Villamayor, Núria. Produtora do programa "Protagonistas" da rádio Onda Rambla. Depoimento à autora. Barcelona, 23/07/97. 
"popularesco», pois também são realizadas entrevistas importantes assim como debates de qualidade. Luís del Olmo, seu condutor, apresenta o programa há mais de 25 anos, tendo iniciado na Rádio Nacional da Espanha, ido posteriormente para a cadeia COPE e, por fim, para a ONDA CERO, sempre levando o programa. Conforme a produtora, após tantos anos, o programa tem vida própria, funcionando à parte da emissora. $\mathrm{Na}$ semana analisada entrevistou o escritor Mario Vargas Llosa, a ministra do Meio-Ambiente, Isabel Tocino, a uma família de artistas, Los Raval, entre outros. Nos assuntos apresentados no decorrer do programa há o predomínio do nacional $(71,5 \%)$ com algum destaque internacional $(28,5 \%)$, sendo destinado pouco espaço para os temas regionais e locais pois, segundo a produtora, «temas locais em princípio não entram uma vez que o programa é nacional». As pautas para o programa são sugeridas pelos produtores e avaliadas por Del Olmo que dá o parecer final.

Sobre os assuntos relativos à União Européia, Núria Villamayor diz que «os temas comunitários são importantes na medida em que são notícia. Tratamos de assuntos da Itália, da Alemanha, etc., mas não há um espaço específico sobre a União Européia».

E exemplifica com o caso dos caminhões com verduras espanholas destruídos pelos franceses e que foram tema de um programa especial. Mas salienta que "nestes seis anos em que estou na produção do programa houve modificações pois, no início, quando se falava sobre a União Européia, as pessoas não sabiam o que era. Hoje, quando se fala em «Euro», analisa-se cada vez mais o que vai ser afetado e quais as modificações que vão ocorrer na economia».

O programa Hoy por Hoy - o mais longo dos três - também possui uma configuração nacional, sendo dirigido para toda a Espanha, desde Madrid. Como entra em rede com as regiões, das $7 \mathrm{~h}$ às $8 \mathrm{~h} 30 \mathrm{~m}$, de meia em meia hora, apresenta um equilíbrio maior que o Protagonistas em relação aos temas regionais. Por ter facilidade em estabelecer conexões, quando há assuntos de interesse das diversas comunidades autônomas, abre espaços com repórteres locais. Mas a sua configuraçāo preponderante é nacional $(63,8 \%)$, seguida pelos temas regionais $(16,2 \%)$ e internacionais $(13,0 \%)$, ficando por último os especificamente locais $(7,0 \%)$. Tanto este programa como os outros dois possuem uma boa rede de correspondentes no exterior e nas regiões. Dos três programas analisados foi o que apresentou maior destaque para os assuntos da União Européia.

A peculiaridade a registrar situa-se na questão da publicidade. As duas emissoras privadas vivem especificamente da mesma. Já a pública carreia verbas das duas fontes; do Governo e da publicidade. Este fato ocorre apenas com as emissoras autonômicas, ou seja, dos governos das regiões, pois a Rádio Nacional da Espanha, com os seus quatro canais, vive apenas do orçamento do país (o que já não ocorre com a TVE que também 
tem duplo financiamento). Segundo o diretor da rádio Onda Rambla, Francesc Olona ${ }^{9}$, "há uma idéia subjacente no país de que a empresa privada há-de vir sempre atrás da pública, que tem a preferência na hora de aceder aos mercados. Mas isto começa a mudar graças às privatizações das grandes empresas».

Olona salienta que o cidadão já aceita pagar seus meios de comunicação públicos não sendo necessário, assim, competir com as empresas privadas na captação de publicidade. "Socialmente isto está aceito. Não há um debate - há um hábito de empresa pública». Um dos motivos para esta aceitação, conforme o diretor, é que a empresa pública de Comunicação é uma grande fonte de postos de trabalho. "A rádio pública deve dar trabalho a umas cinco mil pessoas. A rádio Onda Rambla, por exemplo, privada, tem 100 funcionários, entre colaboradores e contratados. Socialmente isto é interessante mas todos sabemos que é um beco sem saída. Chegará o momento, via União Européia, sobretudo, em que nos obrigarão a 'adelgaçar'. De momento é assim». (Há uma diretiva da UE que diz que até 1999 é permitido o duplo financiamento. Após esta data deverá ser extinto).

\section{Os programas mais ouvidos em Porto Alegre}

Os três programas mais ouvidos, de acordo com dados do IPOPE de março de 1998, analisados em Porto Alegre, foram o Gaúcha Hoje, com 77,4 pontos percentuais de audiência, veiculado no horário das $6 \mathrm{~h}$ às $8 \mathrm{~h}$ da manhã, conduzido por Rogério Mendelski, na rádio Gaúcha Sat. A seguir, foi analisado o programa Flávio Alcaraz Gomes Repórter, da rádio Guaíba $\mathrm{AM}$, com audiência de 16,7 pontos e apresentado das $7 \mathrm{~h} 30 \mathrm{~m}$ às $10 \mathrm{~h}$ por Flávio Alcaraz Gomes. Por fim, na rádio Bandeirantes AM o programa mais ouvido analisado foi o Jornal Gente, com 7,7 pontos de audiência, veiculado entre $7 \mathrm{~h} 30 \mathrm{~m}$ e $9 \mathrm{~h}$ da manhã, com apresentação de Affonso Ritter, Bira Valdez e Políbio Braga.

O programa «Gaúcha Hoje» é irradiado pela Rádio Gaúcha Sat, pertencente à Rede Brasil Sul de Comunicações-RBS. A rede começou a expandir seus veículos de comunicação justamente a partir da rádio Gaúcha. A emissora, fundada em 1927, caracteriza-se por ser a primeira no país a trabalhar 24 horas com informação (incluindo o esporte) e é líder de audiência. Em 1 de março de 1995 a rádio ampliou as suas transmissões em território nacional com a implantação de dois canais no saté-

9 Olona, Francesc. Diretor da rádio Onda Rambla. Depoimento à autora, Barcelona, $30 / 09 / 97$. 
lite Brasilsat B1, passando, então, a ter o nome de Gaúcha Sat e o slogan "A fonte nacional de informação".

Com o sistema via satélite, a emissora montou uma rede de afiliadas 20 no interior do Estado - que recebem a programação normal e mais alguns programas produzidos exclusivamente para a rede Gaúcha Sat. As emissoras integrantes da rede enviam, por telefone, notícias e boletins sonoros, para serem incluídos na programação diária que possui 18 programas fixos, basicamente jornalísticos e esportivos. Aos sábados são nove e aos domingos cinco.

O programa «Gaúcha Hoje» compōe-se basicamente de informaçōes retiradas do jornal Zero Hora (do mesmo grupo RBS), cujos destaques vão sendo analisados pelo apresentador. O programa conta com correspondentes nas principais cidades do país e do mundo. Inclui, ainda, participação de comentaristas «seniores» da emissora, abordando temas de política, economia e gerais. No decorrer do programa, o apresentador comenta as reivindicações dos ouvintes, além das condições do tempo e as manchetes dos principais jornais nacionais.

O outro programa analisado, "Flávio Alcaraz Gomes Repórter», vai ao ar pela rádio Guaíba AM. A emissora foi fundada em 1957, pertencendo, então, ao grupo "Caldas Júnior», proprietário de vários jornais e, posteriormente, de um canal de TV. Atualmente o grupo pertence a Renato Bastos Ribeiro. A crise que causou a venda do Grupo provocou alterações nos jornais que ficaram reduzidos apenas a um, o "Correio do Povo", porém com outro formato. A emissora de rádio, no entanto, prosseguiu com a mesma estrutura, com uma programação voltada ao jornalismo.

O programa iniciou em 1988 e desde o início mantém as mesmas características estruturais e a linha de produção que privilegia os temas locais. $\mathrm{O}$ apresentador normalmente seleciona assuntos de cunho polêmico que podem ser de economia, política, lazer, cultura e serviços. A estrutura do programa baseia-se, principalmente, em entrevistas realizadas pelo apresentador no estúdio ou por telefone, além de fatos do dia que são comentados.

O terceiro programa analisado é irradiado pela rádio Bandeirantes AM de Porto Alegre. A emissora foi fundada em 1934 (é a segunda mais antiga da capital gaúcha) como Rádio Difusora, integrante de uma rede pertencente aos Freis Capuchinhos. Em 1983 a emissora foi negociada com a família Saad, proprietária da Rede Bandeirantes de Rádio e Televisão.

$\mathrm{O}$ «Jornal Gente», que vai ao ar das $7 \mathrm{~h} 30 \mathrm{~m}$ às $9 \mathrm{~h}$, é conduzido por três jornalistas - Bira Valdez, Políbio Braga e Afonso Ritter - que discutem os principais assuntos das últimas horas. $O$ programa inicia com a leitura das manchetes dos principais jornais do país. A partir daí, os apresentadores escolhem os temas e passam a debatê-los. Convém salientar que cada um possui uma característica jormalística própria: Ritter aborda economia, 
Braga, política, e Valdez temas mais gerais. Há também correspondentes que, conforme o tema, entram no programa desde São Paulo, Brasília, Paris, etc. O programa também inclui entrevistas que podem ser no estúdio ou por telefone.

Analisando-se os três programas, do total das 30 horas, verifica-se que o programa "Flávio Alcaraz Gomes Repórter», da rádio Guaíba, é o que aborda mais temas locais, seguido por «Gaúcha Hoje» e, por último, o «Jornal Gente», da rádio Bandeirantes, sendo este o que mais trata de temas internacionais. Em relação aos temas nacionais, há maior destaque nas rádios Gaúcha e Bandeirantes, com um certo equilíbrio. Em relação aos temas sobre o Mercosul, observa-se que do total apenas 10 minutos e cinco segundos trataram do assunto. $\mathrm{O}$ que significa $0,5 \%$ das 30 horas de programação analisadas.

O programa da rádio Gaúcha destinou, durante as cinco edições analisadas, um minuto e 30 segundos de seu tempo - 0,2\% do total - para falar do Mercosul, com uma notícia sobre a Aliança Democrática do Paraguai. O da rádio Guaíba ocupou, no período da análise, três minutos e 30 segundos $-0,4 \%$ do total - quando entrevistou um médico patologista que comentou a regulamentação profissional no âmbito do bloco regional. Já o programa «Jornal Gente», da rádio Bandeirantes, tratou do Mercosul com um comentário sobre a entrada de empresas e capital argentino no país $1,3 \%$ do tempo total. Observa-se que, no período de análise dos três programas, a previsão do tempo na área do Mercosul ocupou mais espaço do que as notícias gerais sobre o bloco econômico: $9,2 \%$ na rádio Gaúcha, $5,4 \%$ na Guaíba e $3,2 \%$ na Bandeirantes.

\section{Considerações finais}

A formação e a consolidação de blocos econômicos regionais na atualidade é um fato. Blocos que se constituem para fazer frente a outros blocos, bem como para resolver questões de circulação de pessoas e produtos, tarifas diferenciadas, investimentos de capitais, comércio, etc. A União Européia consolida-se principalmente com a criação do Euro para fazer frente ao dólar norte-americano e ao yen japonês e, também, para resolver questões internas como a da hegemonia franco-alemã. O Mercosul, por seu turno, estrutura-se não apenas para resolver questões antigas de integração, além da circulação de pessoas e mercadorias, mas, também, para reforçar o poder de negociação dos países que o constituem e para a tomada de decisões internacionais (Iturra,1995). No momento, pode dizer-se que o Mercosul é uma união aduaneira que pretende chegar a tornar-se um mercado comum; já a União Européia é um projeto de construção de uma 
união econômica e monetária que se encontra numa fase de mercado comum (Florêncio e Araújo, 1995).

A organização dos blocos, em geral conduzida por técnicos, privilegia a vertente econômica, deixando de lado as demais questões sócio-políticas e culturais, o que se torna claro na abordagem dos temas relativos ao Mercosul nas emissoras radiofônicas de Porto Alegre. No caso da União Européia, essas questões começam a se tornar visíveis, por exemplo, quando os caminhoneiros transportadores de mercadorias espanholas são barrados na fronteira francesa. Isto porque os acordos de cotas, assinados entre os países do bloco, podem significar menos plantações e postos de trabalho. E só então as questões políticas e culturais viram notícia.

A construção de blocos regionais vai, assim, muito além das questões econômicas. Passa, inclusive, pela assimilação de uma consciência de cidadania mais ampla, extra-fronteiras nacionais. $E$ convém lembrar que «no momento em que economia, política, tecnologia e valores preconizam a abertura e o desmantelamento das separações, assiste-se ao regresso dos temas de identidade, da recusa do outro e até da xenofobia, contra os quais os instrumentos da comunicação parecem ser as melhores defesas» (Wolton, 1994:294). Esta é uma questão que na Europa já é muito presente. No Mercosul, as manifestações ainda são incipientes mas, com o avanço da implantação do mercado comum, deverão crescer, como já ocorreu com a questão da indústria de calçados e de outros produtos comuns às economias dos países integrantes do bloco.

O Mercosul, portanto, sendo ainda uma «união aduaneira», utiliza-se essencialmente de meios econômicos, não contando com um projeto de dimensões políticas que alcance outros domínios da vida social (Meira e outros, 1997). O fato, inclusive, já vem sendo apontado pelos trabalhadores da região. Algumas centrais sindicais aprovaram manifestações, salientando a necessidade de se considerar a integração no contexto mais amplo do desenvolvimento social e da democracia na região.

Por outro lado, as recentes eleiçōes para o Parlamento Europeu, com um elevado índice de abstenção - 53\% - chegando a 76\% na Grã-Bretanha, chamam a atenção para a necessidade de uma reflexão mais profunda. Uma das causas seria a "ausência de paixão pela União Européia, considerada distante e tecnocrática pelos cidadãos" (ZH, 15/06/99, p.39). Mas esta "distância» aponta justamente para o fato da construção do bloco ser prioritariamente econômica e conduzida em geral por técnicos. Uma construçāo, portanto, afastada da sociedade em seus aspectos culturais e políticos.

Por seu turno, a formulação de políticas no setor de telecomunicações tende a deslocar-se, de forma crescente, do controle do Estado para os grandes conglomerados transnacionais, constituindo-se, assim, no elemento-chave dos novos processos globais de produção (Lima, 1998). O que leva a 
várias interrogações: o que ocorrerá com o estado-nação? Como ficará a cultura? Quem terá o poder de decisão? Qual o papel dos meios de comunicação?

A pesquisa realizada junto às emissoras de Porto Alegre e Barcelona, portanto, traz alguns indicativos e não conclusões. Em relação ao papel da mídia, no caso do rádio, constata-se que a pouca presença dos temas referentes ao Mercosul e à União Européia está a demonstrar que a questão ainda não faz parte da vida quotidiana dos cidadãos. Os assuntos de interesse são aqueles que se referem ao dia-a-dia da localidade e da nação e a consciência de pertencer a uma entidade maior que a instância nacional, praticamente inexiste na realidade gaúcha e apenas pontualmente no caso catalão.

Neste sentido, Martíni (1994) considera que um projeto cujo objetivo de análise fosse a realidade cultural implícita nos blocos regionais deveria ter como centro o estudo do imaginário social das representações coletivas e a mudança nas identidades. Para isso, seria necessário examinar-se as pautas de trabalho, produção, legislação e consumo que caracterizam os diferentes setores dos países integrantes, além da reflexão sobre a visão de mundo repassada pelos meios de comunicação, produzida tanto pelos grandes centros de informação como pelas pessoas, por efeitos de sentido comum.

Pode-se dizer assim, concordando com Andrade (1998:349) que, neste momento, o grau de noticiabilidade, no caso do Mercosul, «está na razão direta que o tema tenha a ver com a demanda econômica que ele representa" ${ }^{10}$. No caso da União Européia, cujo bloco possui uma história bem mais longa, outras questões já começam a aparecer, mas a preponderância do econômico ainda é uma realidade, o que, provavelmente, também virá a ocorrer com o Mercosul se este vier, efetivamente, a se transformar em um mercado comum, com todas as suas implicações.

10 Andrade, A e outros. "O Mercosul é notícia?» in Lopes, M. I. e Melo, J. M. (Org.) Poltticas regionais de Comunicaçāo. Os desafios do Mercosul. Londrina, UEL/Intercom,1997. 


\section{REFERÊNCIAS BIBLIOGRÁFICAS}

Brittes, Juçara. Politicas de Comunicaçāo no Mercosul: do nacional ao megaregional. São Bernardo do Campo, Fascículos Umesp de Ciências da Comunicação, 1998.

Florêncio, S. A. e Araújo, E. H. Mercosul Hoje. São Paulo, Alfa Ômega, 1996.

IturRa, Carlos A. Mercosur, Situación y Perspectivas. Montevidéo, Mímeo, 1995.

LıMA, Venício A. «Políticas Regionais de Comunicação: novos atores, velhos problemas», in Lopes, M. I. e Melo, J. M. (Org). Politicas Regionais de Comunicaçāo. Os desafios do Mercosul. Londrina, UEL/Intercom, 1997.

MARTín1, Stella. «Exploraciones del imaginario social en situaciones de cambio: el Mercosur en el marco de los procesos de globalización y localización", in WACC. Comunicacion. Cultura y cambio social. Mercosur y la integración de mercados. Buenos Ayres, WACC, Loyola, 1994.

Melo, José Marques de. «Globalização, multiculturalismo, identidade: os desafios comunicacionais do Mercosul». Montevideo, texto apresentado no Congresso de Relaçóes Públicas no Mercosul, 29/09/1997.

Meira, M. E. e outros. O Mercosul no contexto da integraçāo continental. Porto Alegre, Confea/Ciam/Crea, 1997.

Wolton, Dominique. Elogio do grande público. Lisboa, Ed. Asa, 1994. 